\title{
Short communication: Purple corn (Zea mays L.) stover silage with abundant anthocyanins transferring anthocyanin composition to the milk and increasing antioxidant status of lactating dairy goats
}

\author{
X. Z. Tian, ${ }^{1}$ P. Paengkoum, ${ }^{1 *}$ S. Paengkoum, ${ }^{2}$ S. Chumpawadee,${ }^{3}$ C. Ban, ${ }^{1}$ and S. Thongpea ${ }^{1}$ \\ ${ }^{1}$ School of Animal Technology and Innovation, Institute of Agricultural Technology, Suranaree University of Technology, Muang, \\ Nakhon Ratchasima 30000, Thailand \\ ${ }^{2}$ Program in Agriculture, Faculty of Science and Technology, Nakhon Ratchasima Rajabhat University, Muang, Nakhon Ratchasima 30000, \\ Thailand \\ ${ }^{3}$ Department of Agricultural Technology, Faculty of Technology, Mahasarakham University, Bangkok 44150, Thailand
}

\begin{abstract}
The present study used 16 multiparous lactating Saanen dairy goats (body weight, $41.80 \pm 2.92 \mathrm{~kg}$; mean \pm standard deviation) with healthy and symmetrical udders. Goats were divided into 2 blocks of 8 goats based on milk yield averaged from $75 \mathrm{~d}$ in milk in a randomized completed block design. The 2 study groups were the control (CSSS), in which goats were fed sticky corn stover silage, and the treatment (TPSS), in which goats were fed anthocyanin-rich purple corn (Zea mays L.) stover silage (PSS). The results indicated that the TPSS group led to an elevation in the content of milk lactose relative to the CSSS. The inclusion of anthocyanin-rich PSS had no effect on the level of 5 particular anthocyanins [i.e., cyanidin-3-glucoside, delphinidin, cyanidin, pelargonidin (Pel), as well as total anthocyanins in milk]. The pelargonidin-3-glucoside and malvidin were unable to be detected in both groups. However, the TPSS resulted in higher levels of peonidin (Peo) and malvidin-3-O-glucoside (M3G) compared with the control. Moreover, goats receiving TPSS exhibited a higher level of superoxide dismutase (SOD) in plasma and milk relative to the CSSS. Interestingly, some positive correlations were detected between the certain milk components [i.e., fat and total solids as well as fat and solids-not-fat (SNF); protein and SNF; and total solids and SNF]. In addition, the positive correlations were observed between individual anthocyanins (cyanidin3-glucoside, delphinidin, Peo, M3G, cyanidin, and Pel) and total anthocyanins. Specifically, stronger positive correlations were noted between several antioxidant enzymes and anthocyanin composition in milk (total antioxidant capacity and Pel; SOD and Peo as well as SOD and M3G). Taken together, PSS with abundant
\end{abstract}

Received July 22, 2018.

Accepted September 22, 2018.

*Corresponding author: pramote@sut.ac.th anthocyanins can transfer anthocyanins to the milk and enhance the amount of antioxidants in lactating dairy goats.

Key words: purple corn stover silage, anthocyanin transmission, antioxidant

\section{Short Communication}

Currently, new natural antioxidants are becoming quite popular among consumers because they are safe to consume and have no side effects. Anthocyanins are one source of natural antioxidant compounds and play an important role in improving the antioxidant potential through their ability to scavenge free radicals $(\mathbf{F R})$ that protect against cellular oxidative damage (Canuto et al., 2016).

Small dairy ruminants, such as goats, are more inclined to oxidative stress (OS) because of their intensive metabolic demands for maintenance and production, resulting in damage to their health, leading to mastitis, reproductive disorders, parasitic infections, and a reduction in milk yield (Celi, 2010). One study did show that the OS status of high producing dairy ruminants receiving 5\% polyphenol-rich flax meal can be improved by decreased thiobarbituric acid-reactive substance production and increased nuclear factor-E2related factor 2 mRNA abundance in tissue (Schogor et al., 2013). Specifically, anthocyanins have been reported to show higher levels of 2,2-azinobis-3-ethylbenzotiazoline-6-sulfonic acid and 2,2-diphenyl-1-picrylhydrazyl (DPPH) scavenging activity than other antioxidants (Moo-Huchin et al., 2015).

Our previous work has shown that anthocyanin-rich purple corn stover silage (PSS) had an abundance of anthocyanin composition (Tian et al., 2018). However, anthocyanins showed a low level of bioavailability in animals. To date, no information is available as to whether anthocyanins are absorbed into milk, and if they could thereby improve consumers' health. Our hypothesis is 
vacuum of $36 \mathrm{kPa}$ was used, and a pulsator was operated at $120 \mathrm{cycles} / \mathrm{min}$ with a 50:50 milk:rest ratio. Milk was sampled on the last $2 \mathrm{~d}$ of wk 3 through 8 of the experiment. The samples $(100 \mathrm{~g}$ per $\mathrm{kg}$ of recorded milk yield) were mixed thoroughly and collected at each milking, and the milk $\mathrm{pH}$ value was determined immediately by a portable $\mathrm{pH}$ meter. After that, milk samples were divided into 2 portions. One aliquot was stored at $4^{\circ} \mathrm{C}$ with a preservative (bronopol tablet; D\&F Control Systems Inc., Dublin, CA) until being analyzed for fat, protein, lactose, TS, and SNF using a MilkoScan analyzer (MilkoScan FT2, Foss, Hillerød, Denmark). The other aliquot was stored at $-20^{\circ} \mathrm{C}$ until its anthocyanins and antioxidant activity were analyzed. The following formula from Hamzaoui et al. (2013) was used to calculate 3.5\% FCM: 3.5\% FCM = $\mathrm{kg}$ of milk yield $\times[0.432+0.162 \times($ fat $\%)]$.

At the end of the experiment, blood samples (approximately $3 \mathrm{~mL}$ ) were taken at $0 \mathrm{~h}$ (before feeding) and $4 \mathrm{~h}$ (after feeding) from the jugular vein by Vacuette tubes with $\mathrm{K}_{3}$-EDTA (Greiner Bio-One $\mathrm{GmbH}$, Frickenhausen, Germany). The plasma was transferred to a $1.5-\mathrm{mL}$ tube after centrifugation at $1,788.6 \times g$ for $15 \mathrm{~min}$ at $4^{\circ} \mathrm{C}$, and stored at $-80^{\circ} \mathrm{C}$ until further analysis.

The determination of DM, CP, and ash was performed by the method of AOAC (2005). Neutral detergent fiber and ADF were assayed according to Van Soest et al. (1991). Gross energy was analyzed using an auto-calculating bomb calorimeter (Parr 6200, Moline, IL).

The DPPH scavenging activity was determined by the method of Zarban et al. (2009), using a stable FR DPPH (Pcode: 101845869, Sigma-Aldrich, St. Louis, MO). The enzymatic activities of total antioxidant capacity (TAC), superoxide dismutase (SOD), glutathione peroxidase, and catalase were measured using the commercial kits from Sigma-Aldrich (MAK1871KT, 19160-1KT-F, CGP1-1KT, and CAT100-1KT, respectively).

The individual anthocyanins in the goats' diet and milk were analyzed by the method of Tian et al. (2018), using a HPLC (1260 Infinity II LC, Agilent Technologies, Santa Clara, CA) machine. The preparation of standard curve using commercial anthocyanin composition is as follows: cyanidin-3-glucoside (C3G), delphinidin (Del), pelargonidin-3-glucoside (P3G), peonidin (Peo), malvidin-3-O-glucoside (M3G), cyanidin (Cya), pelargonidin (Pel), and malvidin.

In a previous study on small ruminants receiving a control and anthocyanin-rich plants, the SOD means were 318.7 and $360.2(\mathrm{U} / \mathrm{mL})$, respectively, with a pooled standard error of the mean of 11.7 (Hosoda et al., 2012). The sample size was calculated by SAS 9.1.3
(SAS Institute Inc., Cary, NC). Eight replications were used in the current work, which resulted in a significance level of 0.05 and a power greater than 0.80 . All of the statistical calculations were analyzed using the General Linear Model procedure of SAS 9.1.3 according to a randomized completed block design, using milk yield as the block. Differences between treatment means were detected using Tukey's test with the adjustment for multiple comparisons. Each block was an experimental unit. The relationship between the different milk components and between those and anthocyanins and antioxidant activity parameters were assessed by correlation analyses and analyses of variance. Levels of significance were set at $P<0.05$.

It is known that nutrient digestibility and energy intake are the 2 main factors that affect milk yield. In this study, milk yield of the 2 groups did not differ $(P>$ 0.05; Table 2), whereas the CSSS group showed a higher $(P<0.05)$ SNF production. Indeed, anthocyanin-rich PSS did not affect the DMI, but the feeding time of goats increased whereas the feeding speed decreased in the TPSS treatment during whole trial period because of the bitter taste of anthocyanins. Propionic acid is a precursor to milk lactose content. In the present study, a higher $(P<0.05)$ level of lactose content was noted in the TPSS group, perhaps because anthocyanin-rich PSS was able to affect rumen fermentation, especially inhibiting acetic acid and increasing the proportion of propionic acid in the rumen (Tian et al., 2018). Additionally, the sugars in anthocyanins might be broken down in the digestive tract and be involved in lactose synthesis.

Anthocyanins not only can terminate oxidation via providing protons or electrons to FR, but they also improve the body's antioxidant-related enzyme activity, enhancing the body's antioxidant capacity (Kruger et al., 2014). Thus, the TPSS group had a higher $(P<0.05)$ level of SOD activity, suggesting that the feeding of anthocyanins in dairy goats could improve antioxidants in plasma and milk. Superoxide dismutase is considered the first defense against prooxidants, which can indicate antioxidant potential in ruminants. In addition, superoxide radicals $\left(\mathrm{O}_{2}^{-\bullet}\right)$ are a precursor of mitochondrial hydrogen peroxide $\left(\mathrm{H}_{2} \mathrm{O}_{2}\right)$, which has relatively high toxicity compared with $\mathrm{H}_{2} \mathrm{O}_{2}$. As a result, DPPH scavenging activity, glutathione peroxidase, and catalase were unaffected, perhaps because the high toxicity of $\mathrm{O}_{2}{ }^{-\bullet}$ is converted in the low toxicity of $\mathrm{H}_{2} \mathrm{O}_{2}$ by the SOD enzymes, thereby alleviating OS status. However, the mechanism is not yet resolved.

Anthocyanins can enter into circulation intact, which leads us to assume that when included in the diet, anthocyanins are probably absorbed into the milk. However, anthocyanin absorption appears to be at 
Table 2. Effect of diets on DMI, milk production, milk anthocyanins, and antioxidant activity in dairy goats ${ }^{1}$

\begin{tabular}{|c|c|c|c|c|}
\hline \multirow[b]{2}{*}{ Item $^{2}$} & \multicolumn{2}{|c|}{ Experimental group ${ }^{3}$} & \multirow[b]{2}{*}{ SEM } & \multirow[b]{2}{*}{$P$-value } \\
\hline & CSSS & TPSS & & \\
\hline DMI (g/d) & 886 & 875 & 22.31 & 0.57 \\
\hline \multicolumn{5}{|l|}{ Milk production } \\
\hline Milk yield (kg/d) & 1.57 & 1.53 & 0.02 & 0.15 \\
\hline $3.5 \%$ FCM $(\mathrm{kg} / \mathrm{d})$ & 1.58 & 1.52 & 0.03 & 0.13 \\
\hline Fat $(g / d)$ & 55.75 & 52.90 & 1.62 & 0.23 \\
\hline Protein (g/d) & 52.28 & 50.34 & 0.71 & 0.07 \\
\hline Lactose (g/d) & 70.58 & 69.43 & 0.99 & 0.42 \\
\hline $\mathrm{TS}(\mathrm{g} / \mathrm{d})$ & 189.89 & 181.22 & 3.04 & 0.06 \\
\hline $\mathrm{SNF}(\mathrm{g} / \mathrm{d})$ & $134.14^{\mathrm{a}}$ & $128.32^{\mathrm{b}}$ & 1.96 & 0.05 \\
\hline \multicolumn{5}{|l|}{ Milk component } \\
\hline $\mathrm{pH}$ & 6.49 & 6.45 & 0.01 & 0.07 \\
\hline Fat $(\%)$ & 3.55 & 3.47 & 0.10 & 0.58 \\
\hline Protein (\%) & 3.33 & 3.30 & 0.02 & 0.36 \\
\hline Lactose (\%) & $4.50^{\mathrm{b}}$ & $4.55^{\mathrm{a}}$ & 0.02 & 0.02 \\
\hline $\mathrm{TS}(\%)$ & 12.10 & 11.88 & 0.13 & 0.25 \\
\hline SNF (\%) & 8.55 & 8.41 & 0.05 & 0.06 \\
\hline \multicolumn{5}{|l|}{ Milk anthocyanins (mg/kg) } \\
\hline $\mathrm{C} 3 \mathrm{G}$ & 0.338 & 0.330 & 0.005 & 0.25 \\
\hline Del & 0.959 & 0.959 & 0.003 & 0.93 \\
\hline P3G & - & - & - & - \\
\hline $\mathrm{Peo}$ & $0.371^{\mathrm{b}}$ & $0.388^{\mathrm{a}}$ & 0.005 & 0.01 \\
\hline M3G & $0.446^{\mathrm{b}}$ & $0.457^{\mathrm{a}}$ & 0.003 & 0.007 \\
\hline Сya & 1.283 & 1.290 & 0.004 & 0.16 \\
\hline Pel & 1.042 & 1.041 & 0.002 & 0.83 \\
\hline Mal & - & - & - & - \\
\hline Total anthocyanins & 4.439 & 4.466 & 0.01 & 0.11 \\
\hline \multicolumn{5}{|l|}{ Milk antioxidant } \\
\hline DPPH scavenging activity (\%) & 23.14 & 23.44 & 1.46 & 0.89 \\
\hline $\mathrm{TAC}(\mathrm{nmol} / \mu \mathrm{L})$ & 109.24 & 111.38 & 1.89 & 0.43 \\
\hline SOD (inhibition rate \%) & $82.72^{\mathrm{b}}$ & $90.22^{\mathrm{a}}$ & 0.88 & $<0.0001$ \\
\hline GPX (mmol/min per mL) & 0.324 & 0.333 & 0.02 & 0.79 \\
\hline $\mathrm{CAT}(\mu \mathrm{mol} / \mathrm{min}$ per $\mathrm{mL})$ & 225.93 & 228.26 & 1.60 & 0.34 \\
\hline \multicolumn{5}{|l|}{ Plasma antioxidant ${ }^{4}$} \\
\hline DPPH scavenging activity (\%) & 19.10 & 21.58 & 1.14 & 0.14 \\
\hline $\mathrm{TAC}(\mathrm{nmol} / \mu \mathrm{L})$ & 37.20 & 42.02 & 3.23 & 0.34 \\
\hline SOD (inhibition rate \%) & $91.64^{\mathrm{b}}$ & $96.40^{\mathrm{a}}$ & 0.85 & 0.002 \\
\hline GPX (mmol/min per $\mathrm{mL})$ & 51.64 & 50.36 & 0.69 & 0.22 \\
\hline $\mathrm{CAT}(\mu \mathrm{mol} / \mathrm{min}$ per $\mathrm{mL})$ & 230.82 & 231.28 & 4.39 & 0.94 \\
\hline
\end{tabular}

$\overline{\mathrm{a}, \mathrm{b}}$ Means with different letters within a row are significantly different $(P<0.05)$.

${ }^{1}$ Values for plasma and milk represent the means of 8 replicates $(n=8)$ and 12 replicates $(n=12)$, respectively. ${ }^{2}$ Cyanidin-3-glucoside (C3G), delphinidin (Del), pelargonidin-3-glucoside (P3G), peonidin (Peo), malvidin3-O-glucoside (M3G), cyaniding (Cya), pelargonidin (Pel), malvidin (Mal), 2,2-diphenyl-1-picrylhydrazyl $(\mathrm{DPPH})$, total antioxidant capacity (TAC), superoxide dismutase (SOD), glutathione peroxidase (GPX), and catalase (CAT).

${ }^{3}$ Control, in which goats were fed sticky corn stover silage (CSSS); and treatment, in which goats were fed anthocyanin-rich purple corn stover silage (TPSS).

${ }^{4}$ Values represent the means of 0 and $4 \mathrm{~h}$.

least an order of magnitude lower than that of flavonol quercetin because it is poorly absorbed from the gut and is subject to degradation by intestinal microorganisms. Hence, the amounts of C3G, Del, Cya, Pel, and total anthocyanins in milk were identical $(P>0.05)$. Despite the low absorption, the finding of these anthocyanins in milk may be important due to their unique antioxidant properties for human health. Jordán et al. (2010) showed that component molecular weight was the main factor affected the transfer of polyphenolic components to the milk. This study also indicated that the Cya and Pel were the major types of anthocyanins found in milk. The molecular weights of Cya and Pel are under $300 \mathrm{~g} / \mathrm{mol}$; in contrast, other anthocyanins have molecular weights above $300 \mathrm{~g} / \mathrm{mol}$. In the current work, P3G and malvidin were unable to be detected in milk. The reason may be that they are not absorbed into the milk after ruminant metabolism as well as they had extremely low stability in milk. The TPSS group displayed high $(P<0.05)$ levels of Peo and M3G in milk. Anthocyanins can be absorbed in their intact glycosylated and possibly acylated forms in 
SHORT COMMUNICATION: TRANSFER OF ANTHOCYANIN TO MILK

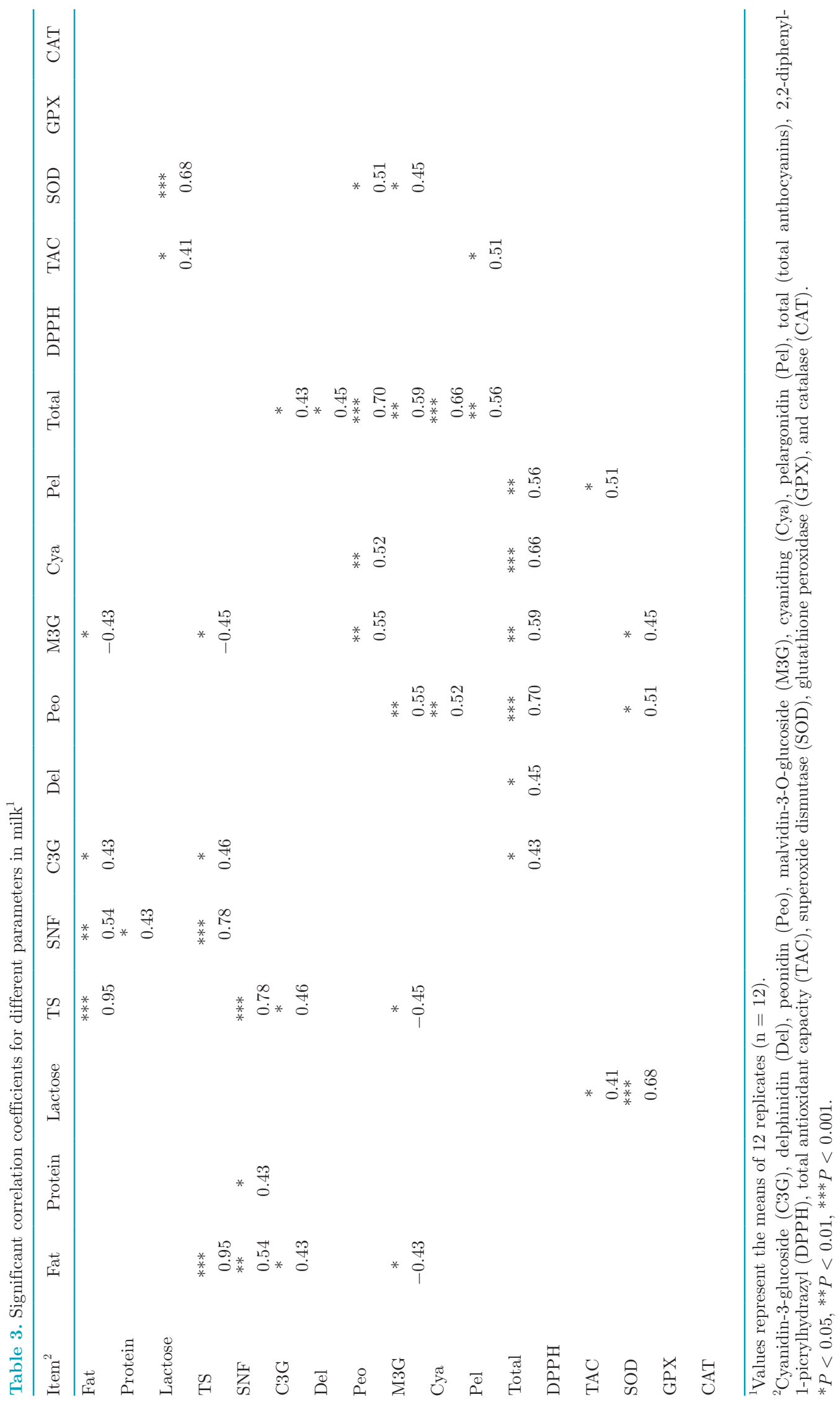


human subjects. Moreover, He et al. (2006) indicated that the type of sugar substitution had a significant effect on the absorption and excretion of individual anthocyanins in rats. These previous reports lead us to presume that Peo and $\mathrm{M} 3 \mathrm{G}$ might have taken part in the acylation reaction of anthocyanin absorption and metabolic mechanism in dairy goats.

Some positive correlations $(P<0.05$; Table 3$)$ were detected between the milk components, such as fat and TS, fat and SNF, protein and SNF, and TS and SNF, perhaps because the general positive association between these components was complemented by the accumulation effects that nutritional forces exert. The content of lactose and TAC as well as lactose and SOD displayed positive correlations $(P<0.05)$. It is likely that the sugar in anthocyanins may be involved in lactose synthesis and metabolism, thereby building a positive relationship with antioxidants in milk. Additionally, the PUFA peroxidation was significantly inhibited in a dose-dependent manner by anthocyanins. Hence, the negative correlations $(P<0.05)$ were noted for the M3G and fat as well as M3G and TS. Significant positive correlations $(P<0.05)$ were observed between Pel and TAC; SOD and Peo as well as SOD and M3G in milk, suggesting that anthocyanins have the potential to enhance the milk antioxidants. Li et al. (2016) indicated that the inclusion of anthocyanins with selenium and vitamin $\mathrm{E}$ showed a synergistic effect in rats. Consequently, the feeding of PSS with abundant anthocyanins had the potential to increase the absorption of other antioxidants. Additionally, the positive correlations $(P<0.05)$ between total anthocyanins and individual anthocyanins (i.e., M3G, Cya, and Peo) were expected. This might be because the bioactivities of anthocyanins can be changed after digestion and enhanced via the synergies between the intestinally digested catabolites.

In summary, anthocyanin-rich PSS can be proposed as a source of roughage in the ruminant diet because (1) it had no negative effect on milk components, (2) it can improve SOD, and (3) anthocyanin composition can be transferred to the milk in lactating Saanen dairy goats.

\section{ACKNOWLEDGMENTS}

This research was provided by the Suranaree University of Technology-OROG (Muang, Thailand) scholarship, the Higher Education Promotion and National Research University Project of Thailand (NRU), and the Office of the Higher Education Commission (FtR 06/2559, Bangkok, Thailand).

\section{REFERENCES}

AOAC. 2005. Official Methods of Analysis of AOAC International. 18th ed. W. Horwitz and G. W. Latimer, ed. AOAC International, Gaithersburg, MD.

Canuto, G. A., D. R. Oliveira, L. S. da Conceição, J. P. Farah, and M. F. Tavares. 2016. Development and validation of a liquid chromatography method for anthocyanins in strawberry (Fragaria spp.) and complementary studies on stability, kinetics and antioxidant power. Food Chem. 192:566-574.

Celi, P. 2010. The role of oxidative stress in small ruminants' health and production. Rev. Bras. Zootec. 39:348-363.

Hamzaoui, S., A. A. K. Salama, E. Albanell, X. Such, and G. Caja. 2013. Physiological responses and lactational performances of latelactation dairy goats under heat stress conditions. J. Dairy Sci. 96:6355-6365.

He, J., B. A. Magnuson, G. Lala, Q. Tian, S. J. Schwartz, and M. M. Giusti. 2006. Intact anthocyanins and metabolites in rat urine and plasma after 3 months of anthocyanin supplementation. Nutr. Cancer 54:3-12.

Hosoda, K., M. Matsuo, M. Miyaji, H. Matsuyama, H. Maeda, H. Ohta, H. Kato, and K. Nonaka. 2012. Fermentative quality of purple rice (Oryza sativa L.) silage and its effects on digestibility, ruminal fermentation and oxidative status markers in sheep: A preliminary study. Grassl. Sci. 58:161-169.

Jordán, M. J., M. I. Moñino, C. Martínez, A. Lafuente, and J. A. Sotomayor. 2010. Introduction of distillate rosemary leaves into the diet of the Murciano-Granadina goat: Transfer of polyphenolic compounds to goats' milk and the plasma of suckling goat kids. J. Agric. Food Chem. 58:8265-8270.

Kruger, M. J., N. Davies, K. H. Myburgh, and S. Lecour. 2014. Proanthocyanidins, anthocyanins and cardiovascular diseases. Food Res. Int. 59:41-52.

Li, X., Y. Zhang, Y. Yuan, Y. Sun, Y. Qin, Z. Deng, and H. Li. 2016. Protective effects of selenium, vitamin E, and purple carrot anthocyanins on D-galactose-induced oxidative damage in blood, liver, heart and kidney rats. Biol. Trace Elem. Res. 173:433-442.

Moo-Huchin, V. M., M. I. Moo-Huchin, R. J. Estrada-León, L. Cuevas-Glory, I. A. Estrada-Mota, E. Ortiz-Vázquez, D. BetancurAncona, and E. Sauri-Duch. 2015. Antioxidant compounds, antioxidant activity and phenolic content in peel from three tropical fruits from Yucatan, Mexico. Food Chem. 166:17-22.

NRC. 1981. Nutrient Requirements of Goats: Angora, Dairy, and Meat Goats in Temperate and Tropical Countries. Natl. Acad. Press, Washington, DC.

Schogor, A. L., M. F. Palin, G. T. Santos, C. Benchaar, P. Lacasse, and H. V. Petit. 2013. Mammary gene expression and activity of antioxidant enzymes and oxidative indicators in the blood, milk, mammary tissue and ruminal fluid of dairy cows fed flax meal. $\mathrm{Br}$. J. Nutr. 110:1743-1750.

Tian, X. Z., P. Paengkoum, S. Paengkoum, S. Thongpea, and C. Ban. 2018. Comparison of forage yield, silage fermentative quality, anthocyanin stability, antioxidant activity, and in vitro rumen fermentation of anthocyanin-rich purple corn (Zea mays L.) stover and sticky corn stover. J. Integr. Agric. 17:2082-2095.

Van Soest, P. J., J. B. Robertson, and B. A. Lewis. 1991. Methods for dietary fiber, neutral detergent fiber, and nonstarch polysaccharides in relation to animal nutrition. J. Dairy Sci. 74:3583-3597.

Zarban, A., F. Taheri, T. Chahkandi, G. Sharifzadeh, and M. Khorashadizadeh. 2009. Antioxidant and radical scavenging activity of human colostrum, transitional and mature milk. J. Clin. Biochem. Nutr. 45:150-154. 